\title{
A lógica do capitalismo nas avaliações externas da educação básica
}

A realidade educacional no contexto da educação básica diante da sociedade capitalista apresenta o desenvolvimento das avaliações externas que proporcionam concorrência, ranqueamento e valorização ou desvalorização das instituições conforme seus resultados mesmo que se tente mostrar outra realidade. Neste trabalho de análise bibliográfica busca-se como objetivo compreender as críticas desenvolvidas sobre as avaliações externas que fundamentam o IDEB conforme seu carácter ranqueador na lógica do capitalismo, sendo que tem-se como problemática saber qual a importância de propor a autoavaliação participativa da escola realizada pela comunidade escolar como forma de proporcionar mas qualidade a educação básica.

Palavras-chave: Avaliação Externas; Capitalismo; Educação básica.

\section{The logic of capitalism in external evaluations of basic education}

The educational reality in the context of basic education in the face of capitalist society presents the development of external evaluations that provide competition ranking and valorization or devaluation of the institutions according to their results, even if trying to show another reality. In this bibliographic analysis work, the objective is to understand the criticisms developed about the external evaluations that base IDEB according to its ranking character in the logic of capitalism, and it is problematic to know the importance of proposing the participative self-evaluation of the school held school community as a way of providing basic education with better quality.

Keywords: External Evaluation; Capitalism; Basic education.

Topic: Políticas Públicas

Reviewed anonymously in the process of blind peer.
Received: 01/06/2020

Approved: 21/09/2020
Eduardo Paiva Oliveira (iD)

Universidade Cidade de São Paulo, Brasil

http://lattes.cnpq.br/8293318835514659

http://orcid.org/0000-0003-3321-4825

edu.paiva@yahoo.com.br
Referencing this:

OLIVEIRA, E. P.. A lógica do capitalismo nas avaliações externas da educação básica. Social Evolution, v.4, n.2, p.1-13, 2020. DOI: http://doi.org/10.6008/CBPC2595-430X.2020.002.0001 


\section{INTRODUÇÃO}

A educação básica na perspectiva da avaliação da aprendizagem pressupõe definir os valores e conhecimentos a serem desenvolvidos, proporcionando a formação do discente e desenvolvendo os métodos de avaliação que ocupam, sem dúvida, espaço relevante no conjunto das práticas pedagógicas aplicadas aos processos de ensino e aprendizagem.

A avaliação externa na educação básica funciona efetivamente conforme lógica do capitalismo, sendo desenvolvido objetivando a realização da avaliação da aprendizagem dos estudantes no ensino brasileiro, pois a importância da avaliação está no contexto das práticas educacionais, sendo uma marca constante em nosso período contemporâneo.

No processo de avaliação da educação básica é importante perceber que os estudantes aprendem de diversas maneiras com base em diferentes recursos, sendo assim o processo avaliativo deve ocorrer de forma satisfatória as necessidades do cidadão e se tornando uma das principais formas de desenvolver os estudantes, contudo as avaliações externas são bastante criticadas no contexto educacional brasileiro.

No decorrer deste trabalho de análise bibliográfica busca-se como objetivo compreender as críticas desenvolvidas sobre as avaliações externas que fundamentam o IDEB conforme seu carácter ranqueador na lógica do capitalismo, sendo que se tem como problemática saber qual a importância de propor a autoavaliação participativa da escola realizada pela comunidade escolar como forma de proporcionar mais qualidade a educação básica.

\section{METODOLOGIA}

A história da Avaliação Educacional afirma-se que a avaliação é por natureza uma disciplina complexa, influenciada por contribuições teóricas da pedagogia, da didática, da psicologia, também da sociologia, da antropologia e da ética (FERNANDES, 2009).

Na linguagem educacional avaliar é uma prática que se encontra na atuação de qualquer educador, pois ao falar sobre a mesma, gera uma ampla e variada discussão que merece ser aprofundada no intuito de saber se este instrumento está contribuindo ou não para promover conhecimento nos alunos ou se este vem excluindo, sendo necessário investigar estratégias metodológicas que diminuam conflitos sobre o que realmente é avaliar, contribuirá para orientar o educador que avaliar não é classificar, mas diagnosticar o aprendizado do aluno bem como de si próprio dentro da realidade cotidiana.

O termo avaliação é de utilização recente, já que a palavra 'exame' era mais frequentemente utilizada para designar provas de conhecimento, que datam aos remotos 1200 A.C as primeiras práticas de avaliação/exame de que temos notícia. Esses exames eram realizados pela burocracia chinesa com intuito de selecionar (somente junto aos homens) aqueles que deveriam ocupar cargos públicos. Desde seus primórdios, portanto, verificamos na avaliação a predominância de um componente seletivo em detrimento a qualquer aspecto educativo.

Sabe-se que, durante muito tempo, a avaliação constitui quase exclusivamente em medir resultados finais de aprendizagem. Assim, a função social da avaliação, quer dizer, a 
certificação das aprendizagens realizadas e a seleção dos estudantes foram muito relevantes que a função pedagógica de análise dos processos e de detenção dos obstáculos ou problemas de aprendizagem. Além disso, muitas práticas de avaliação de antes e de agora estão impregnadas por esse modelo. A ideia de que se pode medir qualquer tipo de aprendizagem e de que avaliar é algo 'técnico', 'preciso', 'objetivo' e inclusive 'científico' aparece como pano de fundo de determinadas concepções de alguns professores sobre a avaliação. (QUINQUER, 2003).

A missão do educador de avaliar é complexa, e exige que o docente seja um exímio observador, capaz de ver o educando, além das aparências, ver a criança, jovem ou adulto em sua totalidade, percebendo os avanços do educando, pois, sempre há avanço, ainda que pequeno, embora muitas vezes o educador não perceba por completo.

O sentido de avaliar é mais amplo na sua essência ao conhecimento, quer dizer diagnosticar por meio de diversas atividades aquilo que o aluno aprendeu ou não ao longo do ano servindo assim para o professor uma análise de si também, passando assim por um processo dialético onde aluno e professor efetuam uma reflexão do ensino e da aprendizagem.

A avaliação é uma tarefa didática necessária e permanente do trabalho docente, que deve acompanhar passo a passo o processo de ensino e aprendizagem. Através dela os resultados que vão sendo obtidos no decorrer do trabalho conjunto do professor e dos alunos são comparados com os objetivos propostos a fim de constatar progressos, dificuldades, e reorientar o trabalho para as correções necessárias. (LIBÂNEO, 1994)

O professor tem buscado se adaptar à realidade educacional do século XXI, porém este desenvolvimento de práticas que contribuam para uma boa avaliação exige uma formação continuada e acompanhada para que todas as aspirações possam chegar à sala de aula.

No processo de avaliação verifica-se que este ato é amplo e não se restringe ao único objetivo, vai além da medida, coloca-se favorável ou desfavorável à ação avaliada, propiciando uma tomada de decisão coerente com a aprendizagem, portanto na essência a avaliação externa não consegue contemplar os requisitos de uma avaliação qualitativa.

No processo educacional as avaliações diagnósticas permitem constatar o que os educandos já sabem antes de começar o trabalho de mais um ano letivo ou de um semestre é essencial para iniciar o planejamento docente, sendo que para garantir que nada seja deixado de lado, é necessário se organizar um cronograma de ações pedagógicas e elaborar um plano semestral com os educadores e educadoras, em que se analisam os dados de cada turma e elaboram-se as avaliações diagnósticas.

A aplicação de uma avaliação diagnóstica colabora na identificação de dificuldades específicas dos estudantes na assimilação ou vivência (no caso da educação infantil) do conhecimento, tanto relacionadas ao desenvolvimento pessoal deles quanto à identificação de quais conteúdo do currículo apresentam necessidades de aprendizagem.

A avaliação diagnóstica deverá estar comprometida com a transformação da realidade e não com a sua conservação, pois ela acompanha a ação pedagógica e pode ser realizada antes como um referencial ao educador, indicando a situação do educando, oportunizando ao docente perceber avanços ou dificuldades, buscando, assim, alternativas para superação do déficit de aprendizagem dos educandos.

No processo de avaliação formativa que inclui a avaliação da aprendizagem que se materializa nos 
contextos vividos pelos docentes e discentes e possui como função, a regulação das aprendizagens, pois para ocorrer essa regulação, é necessário que ela trabalhe com procedimentos que estimulem a participação dos autores do processo, portanto ela baseia-se em princípios, que decorrem do cognitivismo, do construtivismo, do interacionismo, das teorias socioculturais e das sócias cognitivas, trabalhando sob a ótica das aprendizagens significativas.

Já a avaliação somativa acontece ao final dos estudos com a finalidade de verificar o que o educando efetivamente aprende, incluindo conteúdos e vivências mais relevantes e os objetivos mais amplos do período de instrução; visa à atribuição de notas; o relatório descritivo de desenvolvimento no caso de crianças de 0 a 6 anos, fornece feedback ao educando ou seu responsável informando quanto a situação de desenvolvimento/aprendizagem alcançado e se este for o objetivo central da avaliação formativa; presta-se à comparação de resultados obtidos com diferentes educandos, métodos e materiais de ensino. Este tipo de avaliação visa classificar os resultados da aprendizagem alcançados pelos educandos ou seu aparente desenvolvimento ao final do processo.

No contexto de compreensão dos diversos tipos de avaliações existente percebe-se que as avaliações externas não são apenas mais um processo avaliativo qualquer, mas apresenta-se como uma realidade que ganha dimensões sociais alarmante e não tem empoderamento metodológico para desenvolver uma avaliação do estudante na sua totalidade, portanto caracteriza-se como taxativa em uma lógica capitalista.

\section{DISCUSSÃO TEÓRICA}

\section{As avaliações no contexto histórico}

No contexto educacional contemporâneo frente à lógica do capitalismo os indivíduos são cada vez mais submetidos ao processo de avaliação, sendo que durante toda a educação básica os cidadãos brasileiros vivenciam os processos avaliativos internos e externos onde vale destacar o caráter das avaliações em larga escala que são utilizadas como parâmetros para enquadrar os estudantes e unidades educacionais conforme sua proficiência e fortalece assim a ideia de competitividade característico do estado capitalista.

A avaliação do processo de aprendizagem é considerada uma forma de colaborar para uma educação democrática na educação pública, pois possibilita acolher as necessidades dos operários de concorrer numa visão de equidade, sendo esta visão também questionada e criticada, portanto o processo de avaliação do sistema considera em sua matriz referências os parâmetros curriculares nacionais e Base Nacional Comum Curricular focalizando os resultados e as condições para alcançar determinado resultado.

No cenário educacional brasileiro, as avaliações de sistemas começaram a se concretizar em 1990 com a implantação do Sistema de Avaliação da Educação Básica- SAEB, que no decorrer dos anos se integrou ao Índice de Desenvolvimento da Educação Básica -IDEB, com abrangência nacional e posteriormente, considerando nossa tríade do sistema educacional, foi criada a Prova Brasil, de abrangência municipal, que também foi atrelada ao IDEB.

A avaliação de sistema representa claramente dois focos de análises: o primeiro refere-se aos resultados do sistema, as habilidades e competências adquiridas pelos alunos em 
determinadas séries escolares, e o segundo trata das condições oferecidas para alcançar esses resultados. (SOUSA, 2000)

Ao longo dos anos alguns Estados criaram seus próprios sistemas de avaliação como: o SARESP Sistema de Avaliação do Rendimento Escolar em São Paulo; o SIMAVA - Sistema de Avaliação da Qualidade do Ensino e das Escolas em Minas Gerias; o SPAECE - Sistema Permanente de Avaliação da Educação Básica no Ceará.

O processo de aprendizagem nas instituições educacionais tem ampliado bastante os métodos de abordagens diante dos estudantes, sendo uma realidade que acompanha as transformações nas formas de organizar e conceituar as avaliações, pois o processo avaliativo considerado como uma investigação científica é indispensável para colocar em prática nos estados e municípios suas propostas curriculares.

No intuito de avaliar um determinado sistema, etapa, modalidade ou nível de ensino são necessários critérios que considerem alguns pressupostos teóricos e metodológicos relacionados às finalidades educacionais e seus condicionantes culturais, políticos, sociais e econômicas que configuram variadas concepções de indivíduo e sociedade (LIMA FILHO et al., 2012).

O cenário histórico conforme contexto social precisa ser considerado de forma que a avaliação seja realizada considerando fatores além dos instrumentos, recursos, critérios, metodologias, finalidades e outras características adotadas pelo estado como avaliador ou qualquer instituição externa a realidade escolar que assuma esta posição.

De acordo com Guba et al. (2011), a avaliação passou por quatro fases evolutivas, também denominadas de gerações, a primeira geração associada à mensuração, a segunda geração associada à descrição, a terceira geração associada ao julgamento e a quarta geração associada à negociação. Cabe salientar que o modelo teórico avaliativo contido nas gerações de avaliação analisadas por Guba et al. (2011) pode ser aplicado de forma norteadora em estudos de indivíduos, de grupos de indivíduos, programas, materiais institucionais e em sistemas educacionais.

Na primeira geração de avaliação, que nos estudos de Guba et al. (2011) abrange até os anos 1930, há fortes influências do positivismo, de métodos das ciências naturais utilizados em fenômenos sociais, com muitas contribuições do campo da psicologia da educação. É fundamentada nos trabalhos de Francis Galton, Alfred Binet e Théodore Simon.

O trabalho desenvolvido por Galton que em 1882 inaugurou um laboratório de testes em Londres e posteriormente fundou a psicometria dando origem a psicologia diferencial, que tinha por intuito aplicar métodos estatísticos para comprovar as diferenças e heranças humanas de inteligência, esses estudos proporcionaram a utilização de escalas estatísticas para dados de avaliação. Binet e Simon elaboraram uma escala de inteligência que serviu de referência para os testes empregados na área pedagógica. Nesse aspecto, a avaliação passou a ser sinônimo de mensuração, ou seja, de uma medida resultante da aplicação de testes utilizados mediante uma escala padronizada.

No contexto brasileiro, a avaliação como sinônimo de provas e testes é herança desde 1599, trazida para o Brasil pelos jesuítas. Apesar das limitações de seu método, essa geração contribuiu de forma 
significativa na evolução de coleta de dados e produção de instrumentos adequados ao seu propósito, no entanto tornou-se inapropriada na avaliação de programas, métodos entre outros objetos que não fossem o indivíduo.

A segunda geração, compreendida entre 1930 a 1945, e fundamentada pelos estudos de Ralph Tyler (1902-1994) - educador americano que trabalhou no campo da avaliação - propõe que a quantificação seja um meio utilizado para avaliar não se constituindo, ela mesma, a avaliação em si. Sendo assim, a descrição dos objetivos e análise dos dados para verificar o quanto os objetivos propostos foram alcançados ganham destaque. Cabe ressaltar que se denominam objetivos os resultados desejados e, nessa segunda geração, nasce a avaliação de programas educacionais.

As pesquisas de Tyler tinham por finalidade adequar os currículos escolares dos Estados Unidos de acordo com os objetivos estabelecidos pelas necessidades econômicas vigentes na época. Nessa perspectiva a avaliação alcança uma amplitude pedagógica tanto formativa quanto diagnóstica e um caráter orientador. Entretanto, assim como na primeira geração, enfatiza os resultados finais. Caracteriza-se pela semelhança do que hoje conhecemos como avaliação formativa, no entanto com uma reorientação dos pontos a serem ajustados após o final de todo o processo e não no decorrer do processo como é o caso da avaliação formativa e sendo aplicada na análise avaliativa curricular e de programas.

A presença de Tyler foi precursor do programa Eight Year Study, um dos primeiros grandes estudos de avaliação longitudinal, que tinha como um dos objetivos dirimir dúvidas sobre a eficiência diferencial dos vários tipos de escolas atuante nos Estados Unidos, tanto as que propunham um currículo tradicional quanto as que propunham um currículo progressista. Diante da dicotomia entre métodos tradicionais e progressistas, Tyler era alinhado à proposta progressista idealizada por John Dewey (1859-1952), filósofo e pedagogista norte-americano. Seus estudos também procuraram responder aos questionamentos dos Colleges e Universidades sobre a eficiência da proposta curricular progressista, visto que essas instituições temiam que os alunos advindos de escolas com propostas não convencionais, ao chegarem ao ensino superior, não conseguissem acompanhar com eficácia o programa dos cursos oferecidos por essas instituições de nível superior.

A terceira geração, após 1946, pontua a necessidade de julgar todas as dimensões do objeto a ser analisado, não apenas considerando a mensuração e a descrição. Nesse sentido, a avaliação torna-se influenciadora nas tomadas de decisões referentes ao processo educativo. Nesse aspecto é introduzida, por Michael Scriven, a ideia de que a avaliação somativa, associada a prestação de contas que mais tarde, na década de 1980, ganha a perspectiva do conceito de "accountability" no sistema educacional estadunidense, como afirma a pesquisadora Lüdke (1984):

O conceito de 'accountabiiity' teve uma enorme influência no desenvolvimento da avaliação educacional nos Estados Unidos, nas duas últimas décadas. Ele ajudou a encontrar contornos mais precisos para essa disciplina, dentro do domínio da educação, indicando a necessidade do estabelecimento de um acordo entre os que prestam e os que esperam serviços em educação. Assim, a avaliação apareceria como uma espécie de ponte entre os que fazem e os que recebem esses serviços. (LÜDKE, 1984)

No entanto, a mensuração, a descrição e o julgamento não deram conta de toda a complexa atividade 
relacionada à avaliação como afirma Lüdke após estudos realizados na década de 1980, porém sobre as abordagens avaliativas que estavam em discussão nos Estados Unidos, a autora aponta novos caminhos desenvolvidos por Robert Stake e seus associados na Universidade de Illinois revelando o potencial do estudo de caso, entre outras abordagens metodológicas que estavam sendo proposta superando paradigmas:

Falando de maneira geral, as novas abordagens aqui mencionadas, e outras não mencionadas, representam tentativas de enriquecer a avaliação com novos recursos não exatamente antecipados pela abordagem tradicional já estabelecida. Elas quebram a uniformidade das soluções quantitativas usualmente aceitas e utilizadas, liberando uma quantidade considerável de energia criativa, que estava bloqueada pela imposição do velho "paradigma da botânica e agricultura", como diz uma expressiva metáfora, que caracteriza bem um certo período. Permitindo-se buscar novas respostas, vindo de uma variedade de fontes, os avaliadores podem, agora, usar, livremente, sua imaginação para descobrir as melhores soluções para os problemas que enfrentam. Essas soluções podem vir de uma interpretação pessoal, baseada num estudo de caso ou numa crítica educacional, assim como de uma análise estatística estrita, se isso for mais apropriado. Elas podem vir, aliás, de uma combinação desses dois tipos de abordagens, se o problema em questão o exigir. (LÜDKE, 1984)

Nessa abordagem construtivista responsiva destaca-se o estabelecimento de parâmetros e limites da avaliação por meio de processos interativos e negociados que envolvem grupos de interesse, diferentemente das três gerações anteriores cujos parâmetros e limites são pré-estabelecidos a priori em uma relação entre avaliador e cliente, denominada por Stake (1975) como avaliação preordenada. Nesse aspecto a negociação caracteriza essa modalidade avaliativa embasando a Autoavaliação Institucional Participativa.

No contexto histórico a avaliação mesmo diante da quantidade de estudos e pesquisas realizadas ainda permanece em várias realidades na sociedade contemporânea da mesma forma de muitos anos atrás, sendo que o processo avaliativo é colocado como forma de massacrar e reprovar os indivíduos numa visão brutal objetivada pela concorrência capitalista.

\section{Avaliação externa}

No contexto educacional a compreensão de avaliações em larga escala, mas conhecidas como avaliações externas nos direciona a refletir que essas são feitas e organizadas por pessoas que não se encontram inseridos no ambiente interno da escola, ou seja, estas são diferentes das avaliações de aprendizagem de sala de aula, pois por meio de exames de competências encontra-se a objetivação das avaliações externas que é comparar o desempenhos da aprendizagem dos alunos nas aptidões destacadas como importantes para a passagem de etapas do nível de ensino além de apresentar para sociedade capitalista um ranking de qualidade conforme os resultados colhidos com o processo.

Um dos grandes desenvolvedores de avaliações em larga escala são os governos, sendo que o principal foco é obtenção de resultados e assim elaborar novas políticas públicas que favorecem melhorias no sistema de ensino, com isso possibilitando alterações na forma do método pedagógico trabalhado, porém nem sempre está é única visão concebida pela sociedade e dessa forma provoca-se competições e discriminações diante do processo educacional.

O Ministério da Educação e Cultura (MEC), de acordo com Oliveira et al. (2007), é o grande implementador das avaliações externas, buscando uma visão mais abrangente e com isso contribuir com o 
processo de diagnóstico da educação no país, refletindo na busca por melhorias, sendo assim fica evidente o uso no nome avaliação em larga escala, portanto essa avaliação por meio disso precisa ser posta como uma nova maneira de repensar e criar estratégias para potencializar a ação pedagógica.

No cenário educacional brasileiro a avaliação externa ou em larga escala acontece de modos variados tanto pelo método de amostragem como censitário, conseguindo captar informações além do âmbito da sala de aula, pois o MEC procura com este método avaliativo garantir qualidade da Educação, e promover o destaque para o direito da educação a todos.

Essas avaliações informam sobre os resultados educacionais de escolas e redes de ensino a partir do desempenho dos alunos em testes ou provas padronizadas que verificam se estes aprenderam o que deveriam ter aprendido, permitindo inferências sobre o trabalho educativo das escolas e redes de ensino. (BLASIS et al., 2013)

As avaliações externas conseguem recolher dados que revelam as dificuldades que perduram tanto no trabalho desempenhado pelos professores em sala de aula como também no processo de administração da escola, pois assim essas avaliações lançam os locais em que é preciso modificar e desenvolver novas ações numa visão do sistema educacional brasileiro.

De acordo com a concepção de análise realizada por Vianna (2005), ele destaca que:

A avaliação não é um valor em si e não deve ficar restrita a um simples rito da burocracia educacional; necessita integrar-se ao processo de transformação do ensino/aprendizagem e contribuir, desse modo, ativamente, para o processo de transformação dos educandos. (VIANNA, 2005)

$\mathrm{Na}$ avaliação externa é bastante considerado que não se pode apenas focar na medição do grau de qualidade do sistema de ensino, mas precisa ser apontada como ferramenta contribuinte na transformação do ensino, porém em muitos casos essa contribuição não é concretizada na escola, pois de acordo com Gontijo (2011) por mais que o governo se esforce em realizar essas avaliações, elas não são pontuadas como transformadoras do trabalho pedagógico desenvolvido nas escolas brasileiras.

Segundo a concepção de Blasis et al. (2013):

É importante reconhecer que a avaliação externa não termina com a divulgação dos resultados das provas e indicadores. Ela continua à medida que envolve a sociedade, escolas, comunidades e poder público nos debates sobre esses resultados e, a partir disso, abrindo caminho tanto para adensar e dialogar com as avaliações internas realizadas no âmbito das escolas (do projeto pedagógico e da ação educativa), quanto no âmbito das secretarias de educação (das diretrizes da política educacional). (BLASIS et al., 2013)

O desenvolvimento dos procedimentos posteriormente a divulgação dos resultados são fundamentais para sucesso do processo de aplicação das avaliações externas, pois é com isso fica evidente a fundamentação que tem a compreensão do professor sobre a função das avaliações externas e assim ajudar com que as mesmas façam seu papel se concretizar, e tendo o entendimento de que a qualidade do ensino repassado para os estudantes é uma realidade que depende muito das instituições.

A avaliações externas ou avaliações em larga escala como são conhecidas foram introduzidas na sociedade brasileira por volta da década de 90 , ou seja, no século XX, momento em que o ministério da educação iniciou seu processo de investigação sobre as avaliações educacionais.

Os tratados que mencionam em seus contextos escritos sobre educação a exemplo de leis, 
parâmetros curriculares, diretrizes, etc., sendo que as avaliações são ligadas com o processo de procura pela melhoria de potencialidade do ensino, pondo essas em um local onde elas sejam o meio pelo qual se encontra a maior possibilidade de planejar a educação e analisar o andamento das políticas públicas no cenário educacional.

Nos dias atuais as avaliações em larga escala tomaram conta de todo o sistema educacional e tais avaliações são destinadas a investigar a qualidade da educação brasileira em todos os seus níveis, da educação básica ao ensino superior e a pós-graduação.

No contexto educacional dentre as várias avaliações em larga escala aplicada a nível nacional pelo Ministério da Educação e Cultura (MEC) através do Inep (Instituto Nacional de Estudos e Pesquisas Educacionais Anísio Teixeira), podemos citar Avaliação Nacional do Rendimento Escolar (Anresc), mais conhecida como Prova Brasil, a Aneb, que faz parte do Sistema Nacional de Avaliação da Educação Básica (Saeb); o Exame Nacional para Certificação de Competências de Jovens e Adultos (Encceja); o Exame Nacional do Ensino Médio (Enem); o Exame Nacional de Desempenho dos Estudantes (Enade), fazendo parte do Sistema Nacional de Avaliação da Educação Superior (Sinaes).

Os principais focos ou objetivos de todas as avaliações citadas são diversas, pois essas avaliações na medida em que promovem informações sobre o alavancar do trabalho pedagógico nas escolas, deixa também como sua marca o clima competitivo no momento em que mostra os resultados obtidos por cada escola, contudo essa mesma metodologia avaliativa permite que os estudantes caminhem mais à frente nos seus conhecimentos, por se tratar de avaliação que liga o processo de ensino e aprendizagem.

\section{A lógica das avaliações externas no cenário educacional}

Na realidade educacional contemporânea fazer uma avaliação externa das práticas educativas dos gestores, professores, alunos e do ensino como um todo, pode ser um momento crucial para aqueles que estão direta ou indiretamente ligados à educação, sendo que as avaliações em larga escala provocam insegurança no cenário educacional, pois uma avaliação qualitativa não leva em consideração apenas número e no contexto das avaliações externas observa-se que principalmente fundamenta-se na quantidade.

Na aplicação das avaliações externas é possível observa que nem sempre estão realmente atingindo os resultados esperados., sendo que esses medidores da qualidade de ensino nas escolas vêm sendo, de certa forma, para muitas escolas, uma punição e, para outras, um prêmio.

No cenário educacional onde o resultado é positivo, a comunidade, no geral, enxerga a escola com outros olhares, porém se apresentar resultado negativo é vista como uma escola de fracasso que precisa melhorar e, automaticamente, condena a instituição de ensino como um todo, atingindo gestores, professores, alunos, pais e todos que fazem parte da educação escolar, pois essa é uma lógica do capitalismo que seleciona pela quantidade.

$\mathrm{Na}$ discussão sobre as avaliações externas nas unidades escolares existem autores que destacam que as avaliações não podem ser interpretadas como uma punição ou reprovação, pois assim ela deixa de cumprir com sua essência que avaliar nas múltiplas dimensões. 
O desenho e a implementação de sistemas de avaliação externa devem, portanto, ser comparado de discussão e esclarecimento quanto a seus objetivos, a fim de deixar claro que, ao contrário do que fazem professores e escolas, essa avaliação externa não se destina a reprovar ninguém, mas a fornecer informações aos gestores educacionais ao público, sobre o desempenho do sistema como um todo, as escolas, regiões, municípios ou Estado que precisam melhorar seus resultados e o que é necessário fazer para promover essa melhoria. (MELLO, 1993)

Na concepção apresentada acima pelo autor a avaliação externa precisa ser vista com olhares diferentes que a compreenda como parte do processo para fornecer subsídios que favoreça a melhoria do processo de ensino e aprendizagem, porém essa visão ainda é bastante distorcida no contexto educacional e os indivíduos a ver como método de seleção dos melhores e consequentemente reprovação e exclusão dos demais numa visão capitalista.

No caminho educacional acompanhar as aprendizagens dos alunos, ajudando-os no seu percurso escolar através do processo avaliativo qualitativo é uma modalidade de avaliação fundamentada no diálogo, que possui como objetivo, o reajuste constante do processo de ensino, sendo que esta realidade exige muito envolvimento por parte do professor que precisa apresenta bastante disponibilidade de tempo, que vai além do dispensado no momento das aulas, pois entre suas atividades, passa a ser necessária, a construção de um registro sobre cada aluno e a atualização desse registro, sempre que novos dados surgirem, portanto a avaliação externa não consegue desenvolver este trabalho que o professor irá planejar com atenção máxima para atender as necessidades individuais de cada aluno.

De acordo com Libâneo (1994) a prática da avaliação utilizada nas escolas, em sua maioria, está reduzida a uma função de controle mensurado num resultado quantitativo obtido por meio de provas, portanto a lógica capitalista está cada vez mais presente no contexto educacional.

Na sociedade contemporânea desenvolver uma avaliação das ações do cotidiano escolar, investigar os processos implantados, analisarem o que deu certo, revisar os procedimentos, aprimorar o modo de trabalho e obter mudanças naquilo que deu errado, são mecanismos que as unidades escolares poderiam utilizar constantemente, sem ter necessariamente avaliações externas, no entanto, tais avaliações, responsáveis por um diagnóstico de desempenho e qualidade, têm se tornado uma preocupação para muitos profissionais da comunidade escolar.

A realidade é que praticamente todas as propostas de Autoavaliações Institucionais Participativas da educação básica ocorreram em um contexto concomitante à implementação e consolidação das avaliações de sistemas de educação, mais conhecidas no Brasil como avaliações em larga escala, sendo que essas avaliações, também denominadas por avaliações externas, ganharam notabilidade a partir da década de 1990, com o Sistema de Avaliação da Educação Básica- SAEB e os resultados tornaram-se métodos de incentivos fiscais acirrando ainda mais a competitividade.

As avaliações em larga escala são muito relevantes para encaminhamento das políticas públicas, mas podem produzir efeitos indesejáveis com ranqueamento e inflexibilidade curricular e práticas associadas a bonificação de professores, em contrapartida as avaliações institucionais e participativas consideram a realidade local e o conceito de qualidade em uma determinada realidade. 
A noção de avaliação externa na lógica educacional da sociedade contemporânea não consegue afasta-se da realidade capitalista em que vivemos e por mais que se apresente as avaliações como procedimentos de planejamento os cidadãos continuarão tendo a percepção de competitividade.

\section{A realidade capitalista nas avaliações em larga escala}

$\mathrm{Na}$ realidade social capitalista em que vive os cidadãos brasileiros as avaliações em larga escala ou avaliações externas assumem vários campos onde esse debate pode ser citado diante do poder na divulgação dos resultados sobre seus usos, a ligação que faz entre os intuitos das avaliações e as informações produzidas pelas mesmas, assim como os debates políticos e ideológicos em torno do assunto, deixando claro o ar político presentes nessas avaliações. O grau que liga os usos de resultados a sua propagação e disseminação, marcada política e ideologicamente.

A divulgação e espalhamento dos resultados coletados é de grande importância para ocasionar os debates acerca do grau de qualidade da educação, e além disso garantir que as instituições escolares e seus gestores tenham em mão conhecimentos para auxiliar no momento de escolhas, se nota que as práticas de divulgação e propagação das avaliações padrão são largamente debatidas.

Há muitos que criticam o processo das avaliações externas pode fortalecer a lógica capitalista, porém tem muitos defensores da divulgação dos resultados onde existem até os que defendem os ranqueamentos, pois estes mencionam que os usos dos resultados sejam nítidos para o público, mostrando a maneira pela qual as escolas agem e usam dos dotes públicos (CASTRO, 2007).

No momento em que se utiliza as formas técnicas de pontuação das avaliações, é possível que as generalizações acontecem em muitas ocasiões de forma imprópria e a propagação dos resultados acontecem sem uma simples detalhação, onde não conseguem se manter pelo fato por obstáculos no auxílio na gestão dos sistemas educacionais por completo.

Os resultados das avaliações em larga escala também se mostram por um lado positivo para as escolas e sistemas educativos, sendo que nesse posicionamento, as avaliações padronizadas se destacam entre os padrões e possibilidades para o aprendizado dos alunos, caindo bem também como orientador do trabalho escolar.

Nesse contexto das avaliações externas podem ser descritos como condutores para o caminhar do planejamento dos professores, proporcionando aos mesmos vestígios sobre o que fazer e em que momento ensinar aos alunos, amparando a administração da sala de aula.

A atribuição desses testes e seus devidos resultados, acarretam na originação de informações das quais são propiciadas para os professores e as instituições, porém em uma análise crítica favorece as competições e no cenário das escolas com resultados baixos surge o desânimo e falta de perspectiva entre os estudantes, professores e demais funcionários.

Os dados obtidos garantem que as comunidades tenham conhecimento a respeito da qualidade do ensino nas escolas, baseados na ligação aos elementos curriculares avaliados, com isso permitindo aos pais o entendimento sobre os locais de maior qualidade para que seus filhos possam estudar. Os professores e 
estudantes poderiam se engajar na busca por um melhor desempenho, porém é necessário que receba alguma forma de premiação por tal desempenho.

Há autores que se posicionam com visões diferentes, muitos acham que as avaliações não têm uma influência já direta, sendo boas ou ruins, porém podem influir de modo diferente nas escolas dependendo do âmbito em que cada escola se encontra e como são trabalhados os resultados.

De acordo com Madaus et al. (2009), destacam que esses testes nem sempre se mostraram influentes, visto que os professores e alunos em uma boa parte não ligam muito para o resultado dos mesmos. Na visão de Mons (2009), as dificuldades aparecem quando é pego os resultados das avaliações (regionais, estaduais ou municipais) como forma de instrumento administrativo e a medida da realidade dos resultados, pois a gestão dos resultados pode acarretar em problemas que danificam os dados obtidos com a avaliação local.

As avaliações externas nas escolas têm um índice de criticidade muito mais relevante que os argumentos positivos, sendo que muitos autores se posicionam no estudo das consequências negativas, em destaque citam a tomada de decisões a respeito da perenidade dos estudos dos alunos, os recursos financeiros que são proporcionados para as escolas, a beneficiação de professores assim como vários outros usos.

A maioria das críticas estão relacionadas com a influência com que as avaliações posicionam sobre o currículo, o trabalho desenvolvido pela comunidade escolar, e em especial sobre a abordagem dos métodos utilizados pelo professor no ambiente de sala de aula. Um dos grandes pontos levantados como consequência, seria a atenção dada aos conteúdos que não fossem cobrados em tais avaliações, onde os alunos só aprenderiam os conteúdos que os preparasse para obter bons resultados conforme uma lógica capitalista quantitativa.

É destacado com isso que o processo de debates sobre as avaliações em larga escala precisa ser visto com um posicionamento complexo, objetivando com isso fazer com que os sistemas possam desenvolver e produzir dados que possibilitem sobre elevar a utilização política e ideológica que são feitos por meio dos resultados.

No cenário educacional diante das avaliações externa como sociedade capitalista tem-se como foco fazer debate que venha culminar em uma clareza da problemática educacional, fazendo assim acontecer a realização de atos que estejam ligados com o processo de melhoria da educação.

A grande parte das avaliações em larga escala buscam por encontrar dados de medir o nível de aprendizagem dos estudantes brasileiros, em determinadas disciplinas e estabelecer uma relação de correspondência com as condições internas e externas do contexto escolar que venham ou não a potencializar a aprendizagem.

\section{CONCLUSÕES}

O trabalho realizou uma discussão que partiu da definição de avaliações e seus impactos no processo educacional brasileiro, tendo uma visão crítica sobre a forma como as avaliações externas são desenvolvidas 
na educação básica, sendo possível diagnosticar características no processo avaliativo que provocam estímulos à competitividade em um cenário que deveria ser focado na busca por respostas para possibilitar políticas de melhorias no ensino-aprendizagem.

A sociedade ver as avaliações externas como uma realidade que determina o nível do aluno e/ou da instituição de ensino, porém quando se observa a visão dos docentes e estudante verifica-se que ambos reconhecem a importância da avaliação, mas fundamentam uma crítica quanto aos métodos e ao fato de em algumas situações não respeitar o princípio da igualdade de oportunidade tendo por base os fatores que influenciam o ser humano no seu cotidiano vivenciado.

No cotidiano educacional os métodos de avaliações para os estudantes da educação básica torna possível entender que a avaliação apresenta-se como sinal que possibilita a avaliação da situação de aprendizagem dos estudantes no contexto educacional, porém permite compreender que existem inúmeras falhas e descontentamento por parte principalmente dos docentes e estudantes que se sentem prejudicados, pois gostariam de uma forma de avaliar que considerasse as múltiplas aprendizagens desenvolvidas muitas vezes de forma inata e não são consideradas nas avaliações externas.

Conclui-se com este trabalho de análise bibliográfica que as críticas desenvolvidas sobre as avaliações externas que fundamentam o IDEB conforme seu carácter ranqueador na lógica do capitalismo são fatos no cotidiano contemporâneo brasileiro, portanto é importante propor uma autoavaliação participativa da escola realizada pela comunidade escolar como forma de proporcionar, mas qualidade na educação básica e minimizar os efeitos da lógica capitalista no contexto educacional.

\section{REFERÊNCIAS}

BLASIS, E.; FALSARELLA, A. M.; ALAVARSE, O. M.. Avaliação e Aprendizagem: avaliações externas: perspectivas para a ação pedagógica e a gestão do ensino. São Paulo: CENPEC, 2013.

CASTRO, M. H. G.. O desafio da qualidade. In: ITUASSU, A.; ALMEIDA, R.. O Brasil tem jeito?: educação, saúde, justiça e segurança. 2 ed. Rio de Janeiro: Jorge Zahar, 2007. p.35-72.

FERNANDES, D.. Avaliação das aprendizagens em Portugal: investigação e teoria da atividade. Sísifo: Revista de Ciências da Educação, v.9, p.87-100, 2009.

GONTIJO, C. H.. Os resultados das avaliações em larga escala e as percepções de professoras dos anos iniciais do ensino fundamental têm acerca de sua formação e de suas atitudes em relação a matemática: Possíveis conexões. Brasília: Universidade de Brasília, 2011.

GUBA, E. G.; LINCOLN, Y. S.. Avaliação de quarta geração. Campinas: Unicamp, 2011.

LIBÂNEO, J. C.. Didática. 2 ed. São Paulo: Cortez, 1994.

LIMA FILHO, G. D.; TROMPIERI FILHO, N.. As Cinco Gerações da Avaliação Educacional: Características e Práticas Educativas. Revista Científica Semana Acadêmica, v.1, p.121, 2012.
LÜDKE, H. A. M.. O que vale em avaliação. Educação e Seleção, São Paulo, n.9, p.27-36, 1984.

MADAUS, G.; RUSSELL, M.; HIGGINS, J.. The paradoxes of high stakes testing: how they affect students, their parents, teachers, principals, schools, and society. Charlotte: Information Age, 2009.

MELLO, G. N.. Cidadania e competitividade: desafios educacionais do terceiro milênio. São Paulo: Cortez, 1993.

MONS, N.. Theoretical and real effects of standardized assessment. EACEA, 2009.

OLIVEIRA, M. A. M.; ROCHA, G.. Avaliação em larga escala no Brasil nos primeiros anos do ensino fundamental. Associação Nacional de Política e Administração da Educação. Cadernos Anpae, v.4, p.11-14, 2007.

QUINQUER, D.. Modelos e enfoques sobre a avaliação: o modelo comunicativo. Porto Alegre: Artmed, 2003.

SOUSA, C. P.. Dimensões da avaliação educacional. Estudos em Avaliação Educacional, n.22, p.101-118, 2000.

VIANNA, H. M.. Fundamentos de um programa de avaliação educacional. Brasília: Liber Livro, 2005.

A CBPC - Companhia Brasileira de Produção Científica (CNPJ: 11.221.422/0001-03) detém os direitos materiais desta publicação. Os direitos referem-se à publicação do trabalho em qualquer parte do mundo, incluindo os direitos às renovações, expansões e disseminações da contribuição, bem como outros direitos subsidiários. Todos os trabalhos publicados eletronicamente poderão posteriormente ser publicados em coletâneas impressas sob coordenação da Sustenere Publishing, da Companhia Brasileira de Produção Científica e seus parceiros autorizados. Os (as) autores (as) preservam os direitos autorais, mas não têm permissão para a publicação da contribuição em outro meio, impresso ou digital, em português ou em tradução. 